\title{
After the Fall: Can Historical Studies Return to Faculties of Education?
}

\author{
Robert A. Levin
}

A 2000 Canadian History of Education Association (CHEA) panel posed the question, "DoThey Still Teach History in Faculties of Education?" The answer qualifies us for the endangered species list, at least in the United States. There, educational foundations disciplines have been in "retrenchment," if not retreat, in the past two to three decades. A vibrant core of educational-history scholarshipgrows and thrives even so in the remaining educational foundations courses, in departments of History and Sociology, and in such programmes as American Studies and Women's Studies.

The CHEA panel question asked us to reconsider why history belongs in standard Education degree programmes. In my own teaching, I have been led to emphasize curriculum resources that accept the place of "story" in teaching educational history.

\section{HISTORICAL STUDIES IN AMERICAN EDUCATION DEGREE PROGRAMMES}

In the United States, from the early part of the $20^{\text {th }}$ century, history of education in the professional curriculum has aimed, in practice, at producing a kind of survey "exposure," or historical/cultural literacy, among future educators: "for the college student who is entering upon his professional preparation... an orientation to the whole scope of the educational enterprise." But this narrow and traditional goal for historical study - the one that has "stuck" most consistently in U.S. teacher preparation-falls far short of what the authors of those words additionally had in mind for the field at undergraduate and graduate levels and in the public forum. In the preface to their 1953 textbook, A History of Education in American Culture, R. Freeman Butts and Lawrence Cremin wrote:

This book is addressed to all who are interested in the improvement of education in the United States In recent years... individual parents and citizens and organized groups of all kinds are taking a renewed interest in the conduct of schools and colleges...

This book is designed to provide a sound historical foundation upon which to base judgments about American education...It assumes that all present practices and all proposals for the future rest upon some interpretation of the past...

${ }^{5}$ In this paper, the Canadian term "faculty of education" is used interchangeably with the terms more familiar in the United States: schools, colleges, or departments of education in a university or undergraduate college setting. 
In this view the historical approach to educational foundations becomes a reassessing of our cultural and educational traditions. It should help educators make judgments concerning what of our past culture is good for the future and thus needs to be strengthened, and what is destructive of democratic ends and thus needs to be changed. (v-vii)

A History of Education course requirement appears in early records of large universities and rural teacher-preparing "normal schools" dating back at least to the turn of the $20^{\text {th }}$ century. ${ }^{6} \mathrm{It}$ is unlikely those courses provided occasion for critical analyses of the role of educational policies and practices in a democratic society. The consensual and celebratory character of U.S. historical scholarship generally, through the mid-century, would not have encouraged such an approach.

When the field of history began to change, toward the critical perspectives and new analytical frameworks of social history in the 1960 s, programmes-particularly in non-research-oriented universities-were slow to respond. In many of American teacher-preparing institutions, historical studies were-and to the extent they have survived, still are-generalist surveys. This approach accepts our traditional rationale for Social Studies in secondary school, and leads to a similar pedagogy: reliance upon a survey-style, broad-brush textbook laden with names, dates, movements, and events, with an emphasis upon recall of basic information. In the United States, this pedagogy has, for decades, undermined interest in the Social Studies and given to "history" the mantra-like designation, "boring!"

In colleges of education, where educational history or history-and-philosophy courses once had a stable presence, and in particular in the several hundred regional public universities where most American teachers are prepared, historical studies in education have retreated or disappeared. History has fallen victim to more methodologically-oriented programmes and to a declining faith in its purpose or educative potential. Although nearly every accredited Education-degreegranting institution requires some study of "issues" or "broader perspectives" on schooling, the trend is to courses in "multicultural education" that marry pedagogy and (sometimes amateur) sociology.' Education faculty see historical studies as abstract and distant as compared to multicultural studies.

There are, of course, important exceptions to these generalizations. Most of the nation's top 25 research universities have schools of education, and virtually all of those have at least one faculty slot reserved for an education historian. Strong programmes such as those at Wisconsin-Madison, Indiana-Bloomington, and Stanford have more. Another two or three dozen research institutions--some large, some smaller liberal-arts colleges-have recruited faculty with degrees or strong links in education history to fill either methodology or social-foundations generalist positions. Then there are a few dozen smaller regional public and private institutions at which active members of the field are employed. As a group we are strong and

\footnotetext{
'See, for example: Robert A. Levin, Educating Elementary School Teachers: The Struggle for Coberent Visions, 1909-1978. Lanham, MD: University Press of America, 1994.

'Textbooks in multicultural education can be academically sophisticated, but less clear is the extent to which that sophistication may go over the heads both of the students reading them and the generalist instructors often assigned to teach them.
} 
vibrant. On the other hand, our presence spans only about $10-20 \%$ percent of the 1354 institutions that prepare teachers in the United States. ${ }^{8}$

Our field, certainly in the United States and Canada, is vigorously rebuilding its intellectual capacity, if not its foothold in teacher education, to meet Butts's and Cremin's lofty goals of education. Great social and political changes have fuelled changes in the field of historical scholarship generally. Our scholarship has become far more varied and, to most of us, far more interesting since, from the United States perspective, Lawrence Cremin and Bernard Bailyn moved educational history toward social history in the 1960s and 70s. Our colleague Sol Cohen wrote the definitive history of this evolution in his 1976 Harvard Educational Review article.' Over several decades, but especially in the past 15 years or so, educational-history scholarship has blossomed with the arrival of new scholars and new approaches. Some broadbased survey texts, and the recent Historical Dictionary of American Education, now offer students a wider range of interesting material to consider. ${ }^{10}$

Given this background, what case can we make that historical perspective in education matters? With a reconsidered rationale for its role in colleges of education, and a clear sense of our clientele, we can begin to fashion a fresh approach to curriculum and pedagogy to meet our current situation.

\section{A RECONSIDERED RATIONALE AND CURRICULUM FOR HISTORICAL STUDIES IN FACULTIES OF EDUCATION}

Consideration of the Clientele. To construct a rationale for any curriculum, it is useful to look back to Hilda Taba and Ralph Tyler, scholars at mid-century from the University of Chicago. ${ }^{11}$ Among their priorities was a serious consideration of the audience, the clientele, not just the changing field and the social circumstances of our teaching. In United States Education programmes, the clientele is diverse;

${ }^{8}$ For a variety of data about teacher-preparing institutions in the United States, see, for example: C. Emily Feistritzer, "The Making of a Teacher: A Report on Teacher Preparation in the U.S." Washington, D.C.: The National Center for Education Information: wrw.ncei.com/ MOT/MOT-1.btm. The estimate of educational historians' presence at these institutions is an educated guess based upon data from attendance records at national conferences, professionalsociety membership data, etc.

"Sol Cohen, "The History of the History of American Education, 1900-1976." Harvard Educational Review 46 (August 1976): 298-330. See also his Challenging Orthodoxies: Toward a New Cultural History of Education (New York: Peter Lang, 1999).

${ }^{10}$ For example: Wayne Urban and Jennings Wagoner, American Education: $A$ History (McGraw Hill, 1996/2000). Also, Richard J. Altenbaugh, ed., Historical Dictionary of American Education (Greenwood Press, 1999); its 357 entries demonstrate the diversity of the field and its scholars. The textbook publishing of Joel Spring, in the fields of historical and cultural studies in education, has also provided a unique and highly political voice in this regard.

"Hilda Taba, "General Techniques of Curriculum Planning." National Society for the Study of Education, $44^{\text {th }}$ Yearbook, Part I, Curriculum Reconstruction (Chicago: The University of Chicago Press, 1945). Also, Ralph Tyler, Basic Principles of Curriculum and Instruction. (Chicago: The University of Chicago Press, 1949). 
there are also seemingly important differences between the pre-service student profile in the United States compared to Canada.

Canadian and United States teacher educators might begin by noticing a difference between their students. The largest potential clientele for our services in the United States remains at the undergraduate level. In Canada, by contrast, most teacher education occurs at the post-baccalaureate level. In the United States, despite various movements to the contrary, we continue to prepare approximately $72 \%$ of our newly-licensed teachers at the bachelor's-degree level..$^{12}$ One could speculate, therefore, that Canadian students, by virtue of having completed a content-area undergraduate major, may have an important intellectual advantage over United States pre-service students. Canadians presumably would have completed sufficient liberal-arts study to increase the likelihood that they, more than Americans, may have acquired qualities that Social Foundations of Education professors try to impart: a critical perspective on learning and on society, and an appreciation for the inherent inter-disciplinarity of practices and ideas in life and at work. Assessing the clientele should, accordingly, have an impact upon decisions about the appropriate Social Foundations component, and particularly the historical studies component of their teacher preparation.

In the United States, we also have a substantial clientele of in-service teachers, who in most states are required for tenure or continuing contract to obtain a master's degree or its equivalent in continuing-education hours. This large population of working teachers attending "night school" in our Education (and very occasionally discipline-based) master's programmes is a whole other clientele-the early-career or more experienced teacher-for Social Foundations and history professors to serve (in those programmes, of course, where we have an opportunity to do so). Recent data indicate that United States master's degrees in education are the "growth industry" in our programmes. ${ }^{13}$ Typically, the student credit hours a public United States university provides at the master's level results in a much larger per-student taxpayer subsidy than do undergraduate programmes. This makes "night school" for working teachers and administrators a cash cow for faculties of education in the United States, especially as increasing numbers of school administrators pursue post-master's and even doctoral work. Finding a role for history in advanced degree programmes for principals and superintendents raises yet another challenge for our field. ${ }^{14}$

${ }^{12} \mathrm{C}$. Emily Feistritzer, "The Making of a Teacher," 3-4.

${ }^{13}$ 1995-96 may be the first time in our history that United States universities granted more Education master's degrees $(106,253)$ than bachelor's degrees $(105,509)$. C. Emily Feistritzer, "The Making of a Teacher," 4.

${ }^{14}$ In general I am addressing students in College of Education practitioner degree programmes. I am not addressing the very small minority of our students who train to be historians of education at major research universities, where their programmes are housed variously in Education, History, American Studies, Women's Studies, race- or culture-specific studies, etc., or who train in Educational Policy Studies programmes to work in government, international educational development, etc. Nor am I offering specific curricular prescriptions for another small minority: teachers whose advanced degree work is done in their teaching field rather than in Education. 
Taba and Tyler also advocate that, in our planning and goal-setting for appropriate curricula, we consider the discipline and what it specifically could offer to clients. They ask what literatures, sites of knowledge, and methods, from the wide array now present in our field, would enable students most successfully to make use of what we can teach them. Their work further suggests we identify areas in which our students' study might interact with larger social or institutional issues, and that we educate students to make a knowledgeable and socially-sensitive contribution.

I want to suggest a rationale and ideas for teaching historical study to the various clienteles in United States and Canadian programmes. For each area I shall emphasize the role of story in making educational-history studies compelling and applicable. I divide my clientele into three overlapping categories: Advanced studies in school leadership, such as doctoral, post-master's, or other specialized programmes for administrators or teacher-leaders; In-service teacher education, such as post-baccalaureate or master's programmes for practicing teachers to extend their skills or qualify for longer-term certification or tenure; Pre-service teacher education, such as bachelor's degree programmes in the United States and postbaccalaureate programmes in Canada that prepare prospective teachers for their initial licenses.

\section{CURRICULAR RECOMMENDATIONS FOR HISTORICAL STUDIES}

Advanced studies in school leadership: Doctoral or other advanced students in practitioner programmes are often the most goal-oriented in their rationale for advanced study. The most obvious goal in doctoral programmes is successful planning and execution of a dissertation. Applying the $\mathrm{Taba} / \mathrm{Tyler}$ rationale suggests that we accept this starting point, and think how historical study can serve.

In my view, these students should see that any particular matter of policy or practice for which they may be responsible at work, and about which they may be writing a doctoral thesis, has its own important evolutionary story. These students must learn, minimally, how to locate, report on, and take into account historical background evidence that would help to explain how and why any educational policy, program, or initiative began. How have the programme's outcomes compared with its intentions? What values did the policy initially articulate, and in retrospect what values did it promote? How may the policy's direction have differentially have affected various groups in the setting? Have there been clear winners and losers in the programme's story? Whose voices have been sought to answer these questions? Whose have been ignored? With what consequences or potential consequences? I view this pedagogy as something more than "case study" in its concept; I prefer the notion of story because I am interested in the long view of policies and trends and their human and personal as well as institutional and systemic impacts over time. The current movement in United States Education curricula toward a pedagogy of case studies runs the risk of missing the old-growth forest in search of a second-growth tree. 
History is local and national, or global. Most students would rely upon secondary source material and report the results of their research in the first or second chapter, by way of substantive background or review of the literature. But in some topics-multicultural education, gender in education, teacher organizations and unions, among them-biographies, memoirs, and monographs offer rich sources of insight. Further, why not interest at least a few of these doctoral students in making historical development a primary method of inquiry and the central focus of the thesis? These students' research would employ original-source materials, oral histories, and other archival materials that suggest the buman story of administrative or theoretical developments. Educational Administration doctoral students who choose to write historical theses do so in large part to understand how students, teachers, administrators, and communities have shaped and been shaped by a particular school problem or policy. Reconstructing and making sense of such stories becomes a major emphasis of student research.

In-service teacher education: What might a full-time teacher, who perhaps hated history in grade school and college, who can't imagine what it's still doing in the Education course catalogue, and who knows little or nothing of educational history in her own life and work-what might such a person gain from us?

I propose four goals for master's level students in my course on "Educational Challenges in Historical Perspective." Those goals straddle the border between liberal-arts and professional interests:

[1] Students will discover that the work they now do, in several of its personal and institutional dimensions, bas a richly documented history that can be found in what are often surprisingly entertaining and engaging monographs, memoirs, reports, teacher-training textbooks, archival records, curriculummaterial repositories, and so forth, dating back well into the $19^{\text {th }}$ century in almost any medium-sized university library that has a long institutional history of preparing teachers. These resources are often amply supplemented by original-source materials right in their own schools, local history societies, and in the homes of veteran or retired teachers. This matters because, I think, people are rewarded by finding that the work they do has challenged and stimulated people for generations, just as it challenges and stimulates them. People at work like to know they have a history. They are often, if not always, ready to learn.

[2] Students will discover that the educational history of themselves, theirfamilies and communities bas a richness and a freshness shown in our literature. I especially like it when students"place" their own identities, their stories - whether personal, gender, ethnic, cultural, geographic-in the larger story of American education. As a corollary, I ask students to acquire an experience of walking in an other's shoes-of seeing the impact of educational policies and practices upon people whose identity or place in society was or is different from their own. This is best done through an 
appropriate mix of some factual "survey" background, but with the stronger emphasis upon case histories, monographs, memoirs, and the occasional film-all with an eye toward beginning to grasp the general from immersion in the personal.

[3] As with the doctoral students, these master's students will begin to discover that each curricular and policy practice in their schools, districts, and beyond has an origin, the story of which may be instructive in the ways I noted earlier. Teachers typically consider either their belief in a particular policy or practice, or their disagreement with it, in what I see as a personal and non-contextual manner. In either case, the existence of the policy or practice is taken for granted, as a static condition with which one copes. If the teacher is a long-time veteran, one takes for granted not the specific practice, but the inevitability of the process of periodic, mandated "top-down" changes in school priorities.

[4] Students will begin to reconsider at least one educational practice, whether in their own classroom, or in the school or district in light of their historical work, and develop at least a tentative rationale and action plan that could be applied back at school. This goal could lead to something small and classroom-based, such as reconsidering an instructional method, behaviourmanagement procedure, and so on, based on reading and discussion on the origin of that approach. Or, the goal could lead to study of a larger professional or contextual question in the school or district: union goals, priorities, and methods; decision-making processes involving faculty and administration; school-community relations, and so on.

Pre-service teacher education. I turn finally to the undergraduate experience in teacher education, and the presence or absence of history. What is the current status of Social Foundations of Education study generally for these United States students, and historical study in particular?

Estimates suggest that no more than $15 \%$ of United States bachelor's degree programmes in Education have retained such a History of Education course. Even where they exist, few are taught by instructors who have a degree and/or recent experience in the history of education. Most common is a freshman level survey course often called Introduction to American Education, utilizing one of a large number of popular survey textbooks which treat educational history in one to three chapters. These courses are still taught by full-time faculty at some institutions, but very often are taught either by graduate students, or moonlighting or retired school administrators, who work only occasionally in Social Foundations of Education. Also common is a Foundations-oriented course, sometimes narrowly conceived as "multicultural education," but still in 
many places (my own included) called "Education and Society." This course typically enrolls juniors or seniors. ${ }^{15}$

The goals of my undergraduate Educational and Society course, and the range of social-science disciplines that contribute to it, are more various than their master's level analogue. However, I commonly employ story in building a curriculum aimed at educating students in the areas of cultural and other diversities. I am especially interested in our students beginning to experience a "walk in an other's shoes" through the power of story.

The notion of other is a mainstay in academic, professional, and religious thought. In Education, exploring and understanding the other typically appears in our social-foundations literature, often in work on multiculturalism and antiracism. These are good and appropriate places for such study. "Others," it might nonetheless be said, are not identified merely by group identity, but by individual distinction. Thus, a useful story offers the potential of "speaking to" any number of our students, not necessarily because of their racial, ethnic, or gender category, but because children have individuality that a good teacher can grasp. Through story, many of our students will recognize ways their own individuality may have been nurtured or damaged by teachers, and thus help themselves-and, through discussion, their classmates-consider ways they, as teachers, may be able to model or to improve upon.

It is important to emphasize that the best of these materials, and the best of any literature, deals with the universal and unique, to the group and to the individual identity and difference. Here, in part, is the overlap of liberal and professional conceptions in Education and Society. I have never put on my syllabus any of the dozens of "multicultural education" university textbooks currently on the market for teacher-education courses, chiefly because they do not sufficiently attend to both features of the world as we experience it. Teaching about difference and the other, often leading back to teaching about ourselves, is not primarily didactic or linear. It is more properly an engagement in one's own and others' stories, with an analytical framework for considering those stories. That is part of what makes teaching Social Foundations in a college of education so challenging and potentially rewarding, and what makes the place of story so centrally important to those who wish to teach.

${ }^{15}$ It would not be unusual at many institutions for $10 \%$ or more of students enrolled in either the Intro. or the upper-division Foundations course to be post-baccalaureate students who were not Education majors, but are returning to university for state certification to teach. This diversity among the students, along with the increasing population of bachelor's-degree candidates we call "non-traditional-age" (generally late 20 s through 40 s), does have an impact upon matching an historical-studies curriculum to the clientele. 